\title{
The unequal contribution to global energy consumption along the supply chain
}

Jing Menga, ${ }^{a,}$, Xiangping Hu ${ }^{b}$, Peipei Chen ${ }^{\mathrm{c}, \mathrm{d}}$, D’Maris Coffmana, Mengyao Han $\mathrm{d}, \mathrm{e}, \mathrm{f},{ }^{*}$

a The Bartlett School of Construction and Project Management, University College London, London, WC1E 7HB, UK

b Industrial Ecology Programme, Department of Energy and Process Engineering, Norwegian University of Science and Technology, N-7491 Trondheim, Norway

c Institutes of Science and Development, Chinese Academy of Sciences, Beijing 100190, China

d University of Chinese Academy of Sciences, Beijing 100049, China

e Institute of Geographic Sciences and Natural Resources Research, Chinese Academy of Sciences, Beijing 100101, China

f Key Laboratory of Regional Sustainable Development Modeling, Chinese Academy of Sciences, Beijing 100101, China

\section{ABSTRACT}

Reducing fossil fuel consumption is a top priority option for climate change mitigation, which requires collaborations of partners along the supply chain, such as energy suppliers, energy consumers and final consumers of goods and services. A comprehensive analysis of fossil fuel consumption is useful for policymakers to reduce demand but still absent. This study explores the national contribution to global energy consumption from different perspectives in the global supply chain and is designed to complement current energy reduction policies. For the developed countries, energy consumptions are stable from 2000-2014, while that of emerging countries almost doubled (e.g., China and India). Most of the developing countries are producers whose production-based and final production-based energy consumptions are higher than their consumption-based ones, except India after the global financial crisis. In contrast, the developed countries are consumers, whose consumption-based energy consumptions are higher. At the sectoral level, the service sector is the largest contributor to consumption- and income-based

* Corresponding author. E-mail address: hanmy@igsnrr.ac.cn 
energy consumption. The analysis in this study can create opportunities for all the parties alongside the supply chain in reducing fossil fuel consumption.

Keywords: inequality; energy consumption; production-based; consumption-based; income-based

\section{Introduction}

Climate change is one of the biggest and urgent threat to the planet and human societies (Thomas et al., 2004). Fossil fuel combustion is the primary source of global greenhouse gas (GHG) emissions (Davis and Socolow, 2014), which contributes to climate change. However, the need for energy to satisfy social and economic development is increasing (Arto et al., 2016). Climate change mitigation and energy security are two critical challenges toward a sustainable future. In the current trajectory, the world's total energy consumption is projected to rise by $28 \%$ from 575 quadrillion British thermal units (Btu) in 2015 to 736 quadrillion Btu in 2040 (U.S. Energy Information Administration), which challenges the current climate change mitigation actions. Meanwhile, it is reported that energy consumption has contributed to over four-fifths of global anthropogenic carbon emissions (Quadrelli and Peterson, 2007). Therefore, more efforts are supposed to be in place in informing and implanting policies on curbing energy consumptions and the related carbon emissions.

Different methods are used for accounting regional energy consumptions. A traditional method is production-based energy consumption accounting, which measures all energy consumption generated by the production activities of a country (Peters, 2008). However, in a globalized world, final consumptions in one country often cause production and energy consumption elsewhere (Davis and Caldeira, 2010). Considering the interaction of energy consumption and international trade, consumption-based accounting has been proposed to adjust the production-based accounting by adding the energy consumption associated with the production of imports and removing the associated with the production of exports (Malik et al., 2018; Wiedmann and Lenzen, 2018; Wu and Chen, 2017). In this framework, Leontief demand-driven Input-Output (IO) models have been used to help integrate energy consumption and economic activities (Lan et al., 2016). However, challenges remain in adequately characterizing the temporal change of national energy consumption from different perspectives. Furthermore, the link of final consumption of products and services to the producers represents part of the global supply chain so that it is also important to identify the potential for supply-side policies (Marques et al., 2012). 
Downstream responsibility has not been fully addressed in academic literature and corporate sustainability reports (Lenzen and Murray, 2010). In contrast to the Leontief demand-driven 10 models, the Ghosh supply-driven model links production to the primary inputs in the supply chain (Ghosh, 1958; Miller and Blair, 2009). It is characterized by energy consumption enabled by primary suppliers which are required to generate income of a country through wages, profits, and rents (payment to primary factors of production). The supply-side model has been applied to GHG emissions to analyze the forward linkage effects. Marques et al. (2012) quantified income-based environmental responsibility for GHG emissions by 112 regions in the world and compared the results with those obtained from production-based and consumption-based frameworks. Liang et al. (2017) assessed the income-based emissions and constructed new profiles for nations and sectors. Mathematically, income-based accounting adjusts the production-based accounting by removing the domestic energy consumption generated downstream of imported products and adding the foreign emissions generated downstream of exported products. However, downstream responsibility has never received the same attention as its consumption-based cognate.

Meanwhile, energy consumption is induced both domestically and abroad when a country produces final goods and services. Since only final goods enter the domain of consumption, in recent years a final production-based accounting has been raised to associate the energy consumption with the final producing activities. The difference between this and the consumption-based accounting is the agents (final producers or final consumers) that are used to allocate the energy uses. Therefore, for a region that mainly serves as the producer of intermediate products, the energy consumption allocated to it is supposed to be much less than that allocated to a producer of final goods. To identify differences between these methods, Kanemoto et al. (2011) compared emission inventories established under consumption-based, final production-based and production-based accounting frameworks.

Drawing the recent literature on allocating responsibility in different frameworks, this study focuses on energy consumption from different perspectives and is designed to complement current energy mitigation policies. This study complements previous works by identifying national energy consumption at different production stages and sectors to provide insights into energy policies. Specifically, we construct a time-series energy consumption inventory of nations from 2000-2014 from the perspectives of income, production, and consumption. We also reveal the temporal changes and 
sectoral contributions in regional income-based, production-based and consumption-based energy consumption.

\section{Methods and data}

\subsection{Environmentally Extended Input-output Analysis}

This study uses a globally Environmentally Extended Input-output Analysis (EEIOA) to assess the production-based, final production-based, consumption-based and income-based energy consumption of nations from 2000 to 2014. EEIOA was originally developed by Leontief (Leontief, 1970), which is also referred to Leontief demand-driven model and links environmental pressure data to the final consumer of the related products or services. Here, we adopt the framework of Multi-regional Input-Output (MRIO) model which is based on monetary flows to analyze the economic interdependence between different national economies/regions, each composed by many industrial sectors (Davis et al., 2010; Mi et al., 2018a; Rocco et al., 2018). The MRIO model has been widely used in environmental analysis, e.g., greenhouse gases emissions (Meng et al., 2018b; Mi et al., 2017; Vogt-Schilb et al., 2019), air pollutant emissions (Meng et al., 2016b; Meng et al., 2018a; Wang et al., 2019), energy consumption (Chen et al., 2018b), water-energy nexus (Chen et al., 2018a; Zhang et al., 2019), biodiversity (Lenzen et al., 2012), etc., over the past decades.

The typical single region Leontief demand-driven modeling (Meng et al., 2016a; Meng et al., 2015) is based on a sector-by-sector matrix (z) in which the total output $(\mathbf{x})$ required by a certain final demand vector $(\mathbf{y})$ in the region or country under consideration can be described as equation (1):

$$
\mathbf{x}=\mathbf{Z}+\mathbf{y}
$$

The standard MRIO model can be expressed as:

$$
\left(\begin{array}{c}
\mathbf{x}^{1} \\
\mathbf{x}^{2} \\
\vdots \\
\mathbf{x}^{r}
\end{array}\right)=\left(\begin{array}{cccc}
\mathbf{A}^{11} & \mathbf{A}^{12} & \cdots & \mathbf{A}^{1 s} \\
\mathbf{A}^{21} & \mathbf{A}^{22} & \cdots & \mathbf{A}^{2 s} \\
\vdots & \vdots & \ddots & \vdots \\
\mathbf{A}^{r 1} & \mathbf{A}^{r 2} & \cdots & \mathbf{A}^{r s}
\end{array}\right)\left(\begin{array}{c}
\mathbf{x}^{1} \\
\mathbf{x}^{2} \\
\vdots \\
\mathbf{x}^{r}
\end{array}\right)+\left(\begin{array}{c}
\sum_{s} \mathbf{y}^{1 s} \\
\sum_{s} \mathbf{y}^{2 s} \\
\vdots \\
\sum_{s} \mathbf{y}^{r s}
\end{array}\right)
$$

where $\mathbf{X}^{\mathrm{r}}$ is a vector for sectoral total outputs in region $r ; \mathbf{A}^{r s}$ represents the coefficient of industry requirements from region $r$ to $s$ to produce per unit of output $j . \boldsymbol{y}^{r s}$ is the final demand supply from region $r$ to $s$; and $s$ indicates the total number of regions, which is 43 in this study. 
In this framework, production-based accounting assesses a nation's role as a direct consumer, which refers to the energy consumption within the territorial boundary. The production-based energy consumption in region $r$ is:

$$
\mathbf{P}^{r}=\mathbf{E}^{r}(\mathbf{I}-\mathbf{A})^{-1} \mathbf{y}=\mathbf{E}^{r} \mathbf{L y}
$$

Final production-based accounting assesses a nation's role as the final producer, which refers to both direct and indirect energy consumption embodied in the final products of the nation along the whole production chain. The final production-based energy consumption in region $r$ is:

$$
\mathbf{F}^{s}=\mathbf{E}(\mathbf{I}-\mathbf{A})^{-1} \mathbf{y}^{s \bullet}=\mathbf{E L} \mathbf{y}^{s \bullet}
$$

Consumption-based accounting assesses a nation's role as a final consumer (Meng et al., 2017; Yi et al., 2019), which refers to both direct and indirect energy consumption embodied in the products consumed by the nation. The consumption-based energy consumption in region $s$ can be expressed as:

$$
\mathbf{C}^{s}=\mathbf{E}(\mathbf{I}-\mathbf{A})^{-1} \mathbf{y}^{\bullet s}=\mathbf{E L y}^{\bullet s}
$$

where $\mathrm{E}^{\mathrm{r}}$ are the direct energy intensity vector for region $r$ but zeros for all other regions. $\mathrm{E}$ is calculated by each sector's energy consumption divided by the sector's total output $\times$ ( in et al., 2014; Meng et al., 2019). $\mathbf{L}=(\mathbf{I}-\mathbf{A})^{-1}$ is the Leontief inverse matrix, which captures both direct and indirect inputs to satisfy one unit of final demand in monetary value, Leontief MRIO model is regarded as demand-driven. Changes in the final demand initials the upstream outputs. $\mathbf{y}^{\bullet s}$ is the final consumption of products in the region $s$ from each sector of all regions, and $\mathbf{y}^{\text {se }}$ is the final consumption of all regions from region $s$.

\subsection{Supply-side Input-output Analysis}

In contrast to the Leontief demand-driven model, the Ghosh MRIO model is regarded as supply-driven. Changes in primary inputs (e.g., labor and capital) drive downstream production activities (Ghosh, 1958; Liang et al., 2017). Income-based accounting investigates a nation's role as a primary supplier at the beginning of the supply chain, which refers to both direct and indirect downstream energy consumption enabled by its primary inputs of labor, capital, etc. Income-based energy consumption in region $s$ is calculated as:

$\mathbf{D}^{s}=\mathbf{V}^{s}(\mathbf{I}-\mathbf{B})^{-1} \mathbf{E}$

where $\mathbf{V}^{s}$ is the row vector which indicates the primary input of each sector in region $s$. The element $b_{i j}$ of matrix $\mathbf{B}$ is direct sales from sector $i$ to $j$, in terms of unitary output in sector $i$. The matrix $(\mathbf{I}-\mathbf{B})^{-1}$ reflects both direct and indirect 
outputs from various sectors enabled by primary inputs of particular sectors, defined as the Ghosh Inverse matrix.

\subsection{Data sources}

This study uses MRIO tables and sectoral energy consumption data to connect energy consumption to economic activities. The MRIO tables used are from World Input-Output Database (WIOD) released in 2016 (Timmer et al., 2016), which provide detailed interregional transaction information on 44 regions (covering more than $85 \%$ of global GDP), including $28 \mathrm{EU}$ countries and 15 other major economies, and an aggregated "rest of the world" region. However, in this study, the number of regions is 43 because the People's Republic of China and Taiwan are aggregated into one region because of data availability. Each economy in the MRIO table is further divided into 56 sectors. The energy data used in this study are derived from the International Energy Agency (2019), which is also divided into 56 sectors.

The sectoral value-added amounts for 43 regions were derived directly from the MRIO table, consisting of employee compensation, net taxes on production, depreciation of fixed assets and operating surplus. In this paper, the effects of sub-items will not be distinguished, and we merely utilize total value-added (i.e. GDP measured by the income approach) to calculate vector $\boldsymbol{D}$, as shown in equation (6). The economic data from the WIOD are at current prices. To remove the impact of inflation on the monetary output, the producer price index (PPI, National Account Main Aggregates Database) is used to adjust all the monetary data based on prices in the year 2000 to provide a consistent analysis from 2000 to 2014. 


\section{Results and discussions}

\subsection{Regional contribution to global energy consumption}

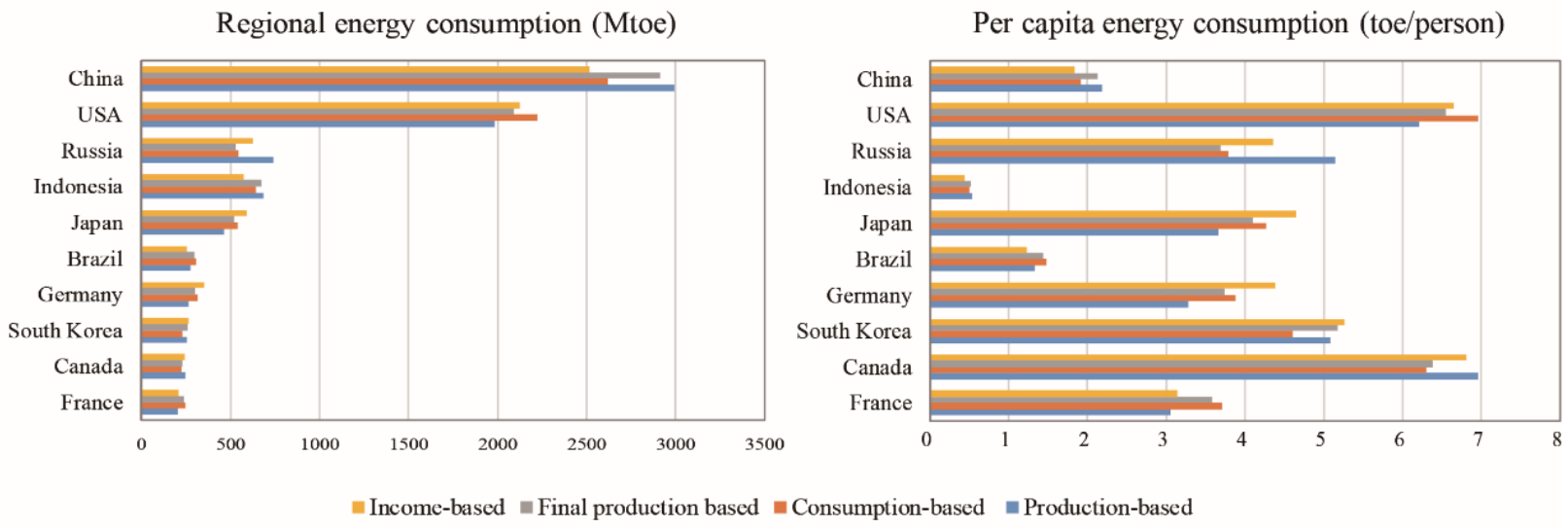

Figure 1. Total and per capita income-, production-, final production- and consumption-based energy consumption of selected 10 regions in 2014.

Figure 1 presents the regional breakdown of fossil fuel energy consumptions in 2014 from all responsibility principles for 10 selected regions, which collectively accounted for about $70 \%$ of the global energy consumption from a production perspective. China is the largest energy user by any measure. Its production-, final production-, consumption-, and income-based energy consumption in 2014 were 2994, 2914, 2619, and 2517 Mtoe (million tonnes of oil equivalent), contributing $24.7 \%, 24.0 \%, 21.6 \%$ and $20.7 \%$ to the total energy consumption, respectively. Compared with the US, the world's second largest consumer, China's shares increased by $50.9 \%, 39.3 \%, 17.8 \%$, and $18.5 \%$, respectively.

In general, production-based energy consumptions are higher than the consumption-based ones for developing regions, such as China, Russia, and Indonesia. The results of energy consumption from final production-based accounting, which depend not only on all related countries' energy intensities upstream, but also the inter-regional production network, reveal different profiles across countries. China and Indonesia shared the same pattern, with final production-based energy consumptions slightly lower than production-based ones, and $10.1 \%$ and $4.4 \%$ less than the consumption-based ones. In Russia, the final production-based energy consumptions were $26.4 \%$ less while $2.8 \%$ more than the production- and consumption-based ones, respectively, while income-based ones were $18.2 \%$ and $15.0 \%$ higher, which indicates that Russia acts more as a primary supplier than as a final seller or final consumer of energy consumption. This is because Russia is a major exporter of resources, such as fossil fuels, which are essential and could induce substantial energy consumptions in downstream 
processes (e.g., electricity generation). Therefore, with the supply-based model, by considering the foreign energy consumption generated downstream of exported products, Russia's energy use is revealed as more than those obtained based on the final production- and consumption-based accounting.

High income-based energy consumptions are observed in other two resource-exporting countries: Japan and Germany. Thus, the important role of resource-exporting (direct or indirect) regions as primary suppliers for global energy consumption is highlighted by income-based accounting. If global energy consumption reduction considers results from the income-based accounting, in addition to those from the production- and consumption-based models, resource-exporting regions should share more responsibilities. This finding informs that supply-side measurement can identify the resource-exporting regions which were overlooked before.

Per capita energy consumptions in developed countries (e.g., the United States, Canada, Japan, France, Germany) were much higher than those in developing regions (e.g., China, Brazil, Indonesia). For instance, the per capita production-, consumption-, final production-, and income-based energy consumptions in the US were respectively $6.21,6.55,6.96$ and 6.65 toe/person in 2014, which were 2.84, 3.08, 3.64 and 3.62 times of those for China. Furthermore, within the developing regions, per capita energy consumption in China was much higher than those in Brazil and Indonesia from all perspectives. 


\subsection{Temporal trends in regional energy consumption}
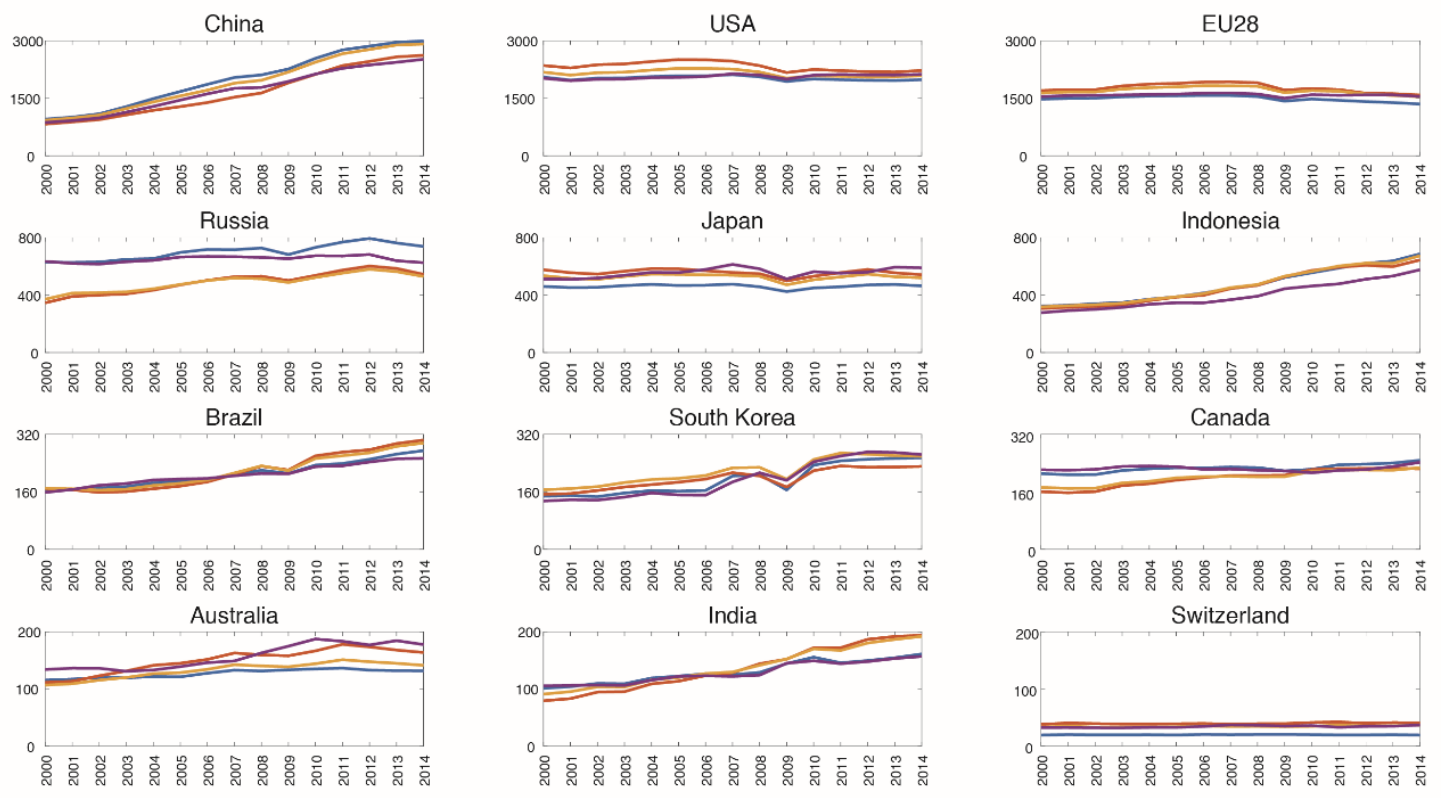

—Production-based — Consumption-based —Final production-based

- Income-based

(Unit: Mtoe)

Figure 2. Energy consumptions of selected regions over the period 2000-2014.

Global total fossil-fuel energy consumption witnessed rapid growth, from $8.4 \times 10^{6}$ Mtoe in 2000 to $1.2 \times 10^{7}$ Mtoe in 2014. Energy consumptions of developing regions kept growing during 2000-2014 (Figure 2), mainly due to their increasing primary inputs (e.g., capital and labor forces) to promote economic development. Since 2012, the growth rate of China's energy consumption has been stable due to the changes in the energy mix and industrial structure (Guan et al., 2018; Mi et al., 2018b).

Income-based energy consumptions of China, Indonesia, India, and Brazil in 2014 increased by $190 \%, 108 \%, 49 \%$, and $60 \%$, respectively, compared with 2000 levels. This shows these developing regions gained increasing benefits from both energy consumption income and by serving the providers of primary inputs. Since the 1990s, China has implemented a series of policy incentives (e.g., tax exemption) to attract foreign investment. Besides, the constant migration of rural peasants into urban areas in China has satisfied the increasing labor needs of domestic industries for producing the exported commodities. The robust investment and low-cost labor have led to the booming economic growth of the Chinese economy, whose income in the form of payment to primary factors of production has increased by around nine times from 2000 to 2014 according to the World Bank. Therefore, income-based energy consumptions of China nearly tripled during this time-span. Even around 2007 or 2008, the effect of the global financial crisis on income-based energy consumption in China is very limited. 
The energy consumptions of developed regions remained relatively stable during 2000-2014, except for Australia and South Korea, whose income-based energy consumption in 2014 increased by $33 \%$ and $96 \%$ than 2000 levels, respectively (Figure 2). This demonstrates the economies of developed regions have been in a comparatively steady state during the last decade except that there was a short-term drop during the global financial crisis. However, the energy consumption rebounded in 2010 because of the rapid easing of energy prices and substantial investment in many countries (Peters et al., 2012).

\subsection{Indicator change}

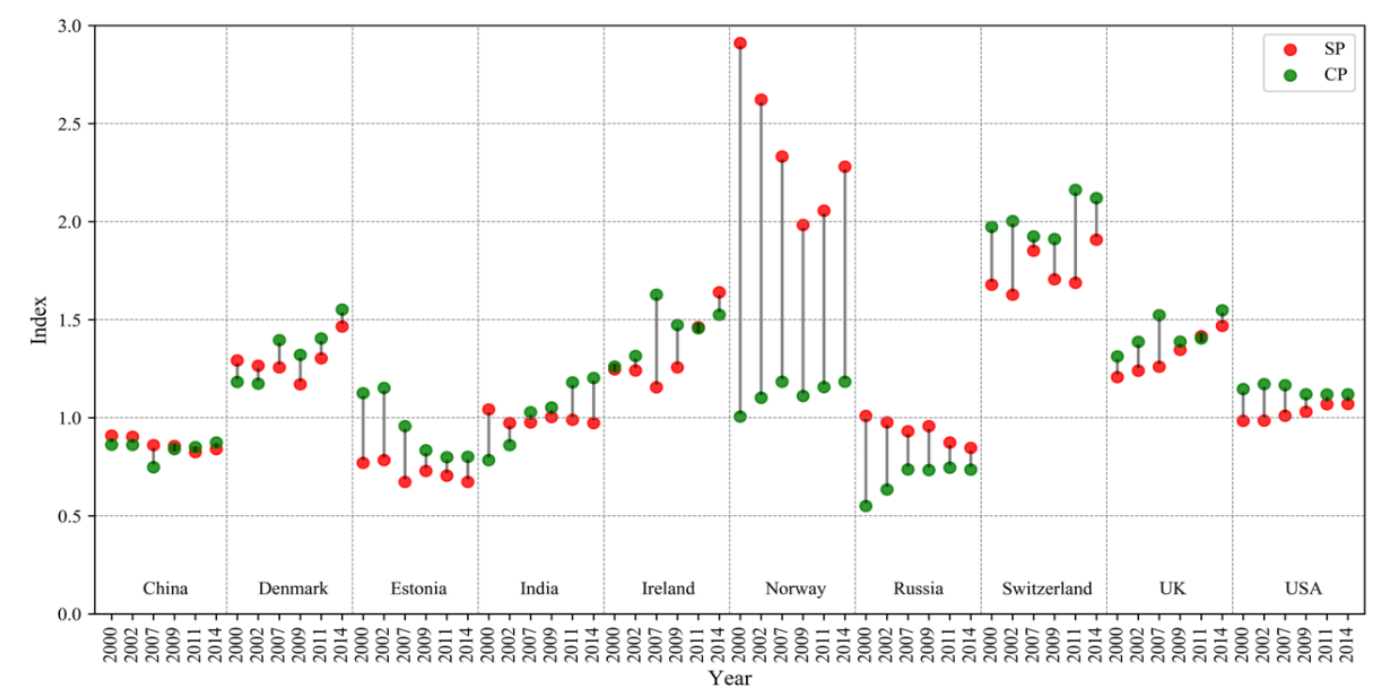

Figure 3. The evolution of role in driving energy consumption of selected countries $(\mathrm{SP}=$ income-based $/$ production-based energy, $\mathrm{CP}=$ consumption-based / production-based energy).

Figure 3 shows the temporal change of indictors in turning points for selected countries. As consumption-based accounting sheds light on how energy is required to generate final demand, income-based accounting sheds light on how energy is enabled to generate income. We define two indicators here, one is SP, the ratio of income-based energy to production-based energy, is used to compare the role of a country as a supplier or producer. The other one is CP, the ratio of consumption-based energy to production-based energy is used to compare the role of a country like a consumer or a producer. These indicators can help us clearly understand the role of each country in driving energy consumption and how they evolve.

We find that, for some countries, responsibility values varied substantially when applying different allocation methods, while for some other countries they were comparable. Notably, the contributions of Norway as a producer and 
consumer were comparable ( $\mathrm{CP} \approx 1$ ), but the energy consumption from the income-based accounting was 2-3 times of that the production-based one. However, the big gap has shrunk from 2000 to 2014. This indicates that income-based responsibility can complement production- and consumption-based responsibility in some cases by highlighting countries that were overlooked before as resource-exporting countries.

For developed countries in Europe, the income-based and consumption-based energy consumption were all larger than the production-based energy (SP, CP > 1), while the difference was much larger for Switzerland (SP, CP $\approx 2$ ). For developing countries such as China and Russia, their consumption-based energy consumptions were less than the production-based ones $(\mathrm{CP}<1)$, while the gaps were shrinking. However, their gaps between income-based and production-based energy consumption (SP) were widening during 2000-2014. Though India is a developing country, its consumption-based energy consumption has outpaced the production-based one (CP $>1)$ after global financial crisis, because of the escalating final consumption. In contrast, India's incomed-based energy consumption was comparable to the production-based energy consumption during the last two decades.

\subsection{Sectoral contributions in different perspectives}




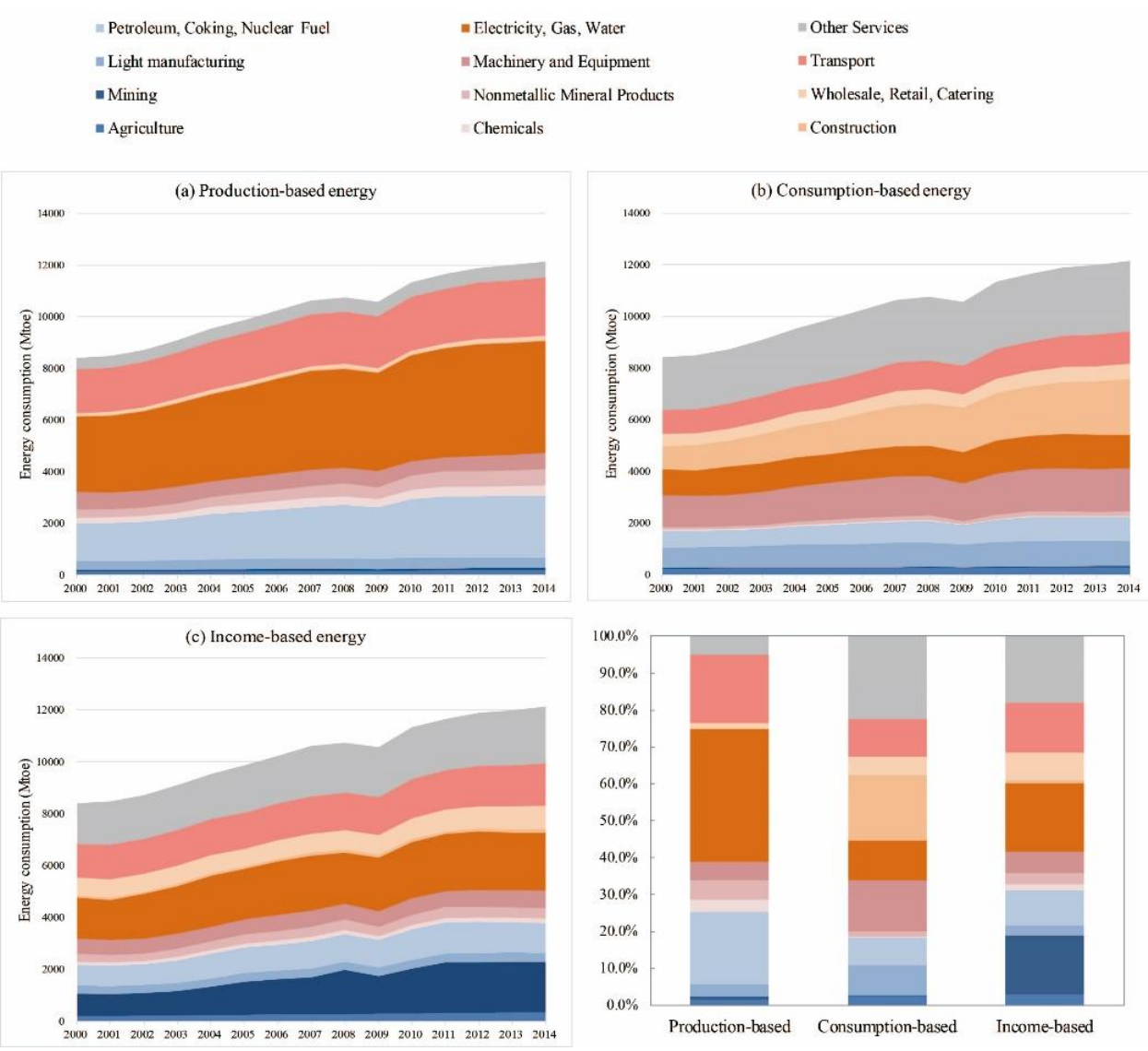

Figure 4. Temporal change in sectoral energy consumption from (a) production-, (b) consumption-, (c) income-based accounting and (d) comparison of sectoral contribution in 2014.

A sectoral breakdown for energy consumption from different perspectives (Figure 3) shows different profiles. The top 20 sectors in income-based energy consumption are mainly related to basic materials (i.e., agriculture, mining, metal, and electricity) and manufacture-related services. These sectors located upstream of the supply chain are critical to industrial production and result in significant downstream energy consumption. Besides, these sectors mainly locate in regions with high GDP, i.e., in the US, China, India, Russia, and Brazil. In summary, under the income-based accounting, the major contributors were electricity $(18.4 \%)$, other services (18.1\%), mining (16.1\%) and transport sector (13.4\%). The biggest sectoral contributor to global production-based accounting was electricity (35.7\%), followed by petroleum, coking and nuclear fuel (18.7\%) and the transport sector (18.7\%). Under consumption-based accounting, the main contributors were other services (22.4\%), construction (17.7\%), machinery and equipment (13.7\%), electricity $(10.89 \%)$ and transport sector (10.4\%). Under the consumption-based and income-based accounting, the service sector (including transport, wholesale and other services) respectively shared $37.5 \%$ and $38.9 \%$ of global total energy consumption, compared to a ratio of $24.8 \%$ under the 
production-based one. Therefore, the tertiary industries as a major beneficiary of income and the supplier of high value-added consumer products should take more responsibility in curbing energy consumption.

\section{Conclusion and policy implications}

This study aims to clarify the role of each region as a supplier, producer, final producer and final consumer in energy consumption. The analysis of national development characteristics and contribution along the global supply chain from different points of view provides a more comprehensive understanding of how energy consumption can be curbed.

The new finding in this study can be summarized as 1) Global energy consumption increased rapidly, and China is the largest energy user from all perspectives. For the developed countries, energy consumptions were stable from 2000-2014, while that of emerging countries almost doubled. 2) Most of the developing countries are producers, whose production- and final production-based energy consumptions are higher than their consumption-based ones. In contrast, the developed countries are consumers, whose consumption-based energy consumptions are higher. 3) At the sectoral level, the service sector is the biggest contributor to consumption- and income-based energy consumption.

The policy implications are also different because of the diverse trajectory across countries. China and Russia serve as producers and they use energy for the production of goods or services. Therefore, more efforts should be emphasized on improving energy efficiency. This applies especially to China since it is the largest energy consumer in the world. Norway is an important supplier of resources, which enables the energy consumption of downstream countries.

From a consumption-based perspective, importing countries can improve their environmental preference by selecting producers abroad with higher energy efficiency. Recent studies have suggested that changes in lifestyles and consumer choices are necessary to reduce environmental pressures (Hubacek et al., 2007; Wiedenhofer et al., 2017). For example, He et al. (2018) has shown that increasing consumption of meat, cooking oil and other-starchy foods would drive the environmental burdens, which can be addressed by changing the daily diet habits.

Based on this study, we can identify some possible future researches. In supply-side, we can further explore the upstream and downstream links of the supply chain and international trade and then consider adopting more targeted 
policies to complement or replace production-side and demand-side approaches. Besides, the feasibility and effectiveness of policy implementation should be conducted based on these different frameworks of energy consumption.

\section{Acknowledgments}

This work was supported by the National Natural Science Foundation of China (41701135).

\section{Reference}

International Energy Agency. (2019). International Energy Agency World Energy Balances, 1960-2018. [data collection]. 8th Edition. UK Data Service. SN: 6301,

http://doi. org/10.5257/iea/web/2019.

Arto, I., Capellán-Pérez, I., Lago, R., Bueno, G., Bermejo, R., 2016. The energy requirements of a developed world. Energy Sustain Dev 33, 1-13.

Chen, B., Han, M., Peng, K., Zhou, S., Shao, L., Wu, X., Wei, W., Liu, S., Li, Z., Li, J., 2018a. Global land-water nexus: agricultural land and freshwater use embodied in worldwide supply chains. Sci. Total Environ. 613, 931-943.

Chen, B., Li, J., Wu, X., Han, M., Zeng, L., Li, Z., Chen, G., 2018b. Global energy flows embodied in international trade: A combination of environmentally extended input output analysis and complex network analysis. Appl. Energy 210, 98-107.

Davis, S. J., Caldeira, K., 2010. Consumption-based accounting of C02 emissions. Proc. Natl. Acad. Sci. 107, 5687-5692.

Davis, S. J., Davis, S. J., Caldeira, K., 2010. Consumption-based accounting of C0 2 emissions.

Davis, S. J., Socolow, R. H., 2014. Commitment accounting of C02 emissions. Environ. Res. Lett. 9, 084018.

Ghosh, A., 1958. Input-output approach in an allocation system. Economica 25, 58-64. Guan, D., Meng, J., Reiner, D. M., Zhang, N., Shan, Y., Mi, Z., Shao, S., Liu, Z., Zhang, Q., Davis, S. J., 2018. Structural decline in China' s C02 emissions through transitions in industry and energy systems. Nat. Geosci. .

He, P., Baiocchi, G., Hubacek, K., Feng, K., Yu, Y., 2018. The environmental impacts of rapidly changing diets and their nutritional quality in China. Nature Sustainability $1,122$.

Hubacek, K., Guan, D., Barua, A., 2007. Changing lifestyles and consumption patterns in developing countries: A scenario analysis for China and India. Futures 39, 1084-1096. Kanemoto, K., Lenzen, M., Peters, G. P., Moran, D. D., Geschke, A., 2011. Frameworks for comparing emissions associated with production, consumption, and international trade. Environ. Sci. Technol. 46, 172-179. 
Lan, J., Malik, A., Lenzen, M., McBain, D., Kanemoto, K., 2016. A structural decomposition analysis of global energy footprints. Appl. Energy 163, 436-451. Lenzen, M., Moran, D., Kanemoto, K., Foran, B., Lobefaro, L., Geschke, A., 2012. International trade drives biodiversity threats in developing nations. Nature 486, 109-112.

Lenzen, M., Murray, J., 2010. Conceptualising environmental responsibility. Ecol. Econ. 70, 261-270.

Leontief, W., 1970. Environmental repercussions and the economic structure: an input-output approach. The review of economics and statistics 52, 262-271.

Liang, S., Qu, S., Zhu, Z., Guan, D., Xu, M., 2017. Income-Based Greenhouse Gas Emissions of Nations. Environ. Sci. Technol. 51, 346-355.

Lin, J., Pan, D., Davis, S. J., Zhang, Q., He, K., Wang, C., Streets, D. G., Wuebbles, D. J., Guan, D., 2014. China' s international trade and air pollution in the United States. Proc. Nat1. Acad. Sci. 111, 1736-1741.

Malik, A., McBain, D., Wiedmann, T.0., Lenzen, M., Murray, J., 2018. Advancements in Input - Output Models and Indicators for Consumption - Based Accounting. J. Ind. Ecol. . Marques, A., Rodrigues, J., Lenzen, M., Domingos, T., 2012. Income-based environmental responsibility. Ecol. Econ. 84, 57-65.

Meng, J., Liu, J., Guo, S., Huang, Y., Tao, S., 2016a. The impact of domestic and foreign trade on energy-related PM emissions in Beijing. Appl. Energy 184, 853-862.

Meng, J., Liu, J., Xu, Y., Guan, D., Liu, Z., Huang, Y., Tao, S., 2016b. Globalization and pollution: tele-connecting local primary $\mathrm{PM}\langle\mathrm{sub}\rangle 2.5</ \mathrm{sub}\rangle$ emissions to global consumption. Proceedings of the Royal Society A: Mathematical, Physical and Engineering Science 472.

Meng, J., Liu, J., Xu, Y., Tao, S., 2015. Tracing Primary PM2. 5 emissions via Chinese supply chains. Environ. Res. Lett. 10, 054005.

Meng, J., Liu, J., Yi, K., Yang, H., Guan, D., Liu, Z., Zhang, J., Ou, J., Dorling, S., Mi, Z., Shen, H., Zhong, Q., Tao, S., 2018a. Origin and Radiative Forcing of Black Carbon Aerosol: Production and Consumption Perspectives. Environ. Sci. Technol. 52, 6380-6389. Meng, J., Mi, Z., Guan, D., Li, J., Tao, S., Li, Y., Feng, K., Liu, J., Liu, Z., Wang, X., Zhang, Q., Davis, S. J., 2018b. The rise of South - South trade and its effect on global C02 emissions. Nature Communications 9, 1871.

Meng, J., Mi, Z., Yang, H., Shan, Y., Guan, D., Liu, J., 2017. The consumption-based black carbon emissions of China's megacities. J Clean Prod 161, 1275-1282.

Meng, J., Yang, H., Yi, K., Liu, J., Guan, D., Liu, Z., Mi, Z., Coffman, D. M., Wang, X., Zhong, Q., Huang, T., Meng, W., Tao, S., 2019. The Slowdown in Global Air-Pollutant Emission Growth and Driving Factors. One Earth 1, 138-148.

Mi, Z., Meng, J., Guan, D., Shan, Y., Song, M., Wei, Y., Liu, Z., Hubacek, K., 2017. Chinese $\mathrm{C} 02$ emission flows have reversed since the global financial crisis. Nature communications 8, 1712 . 
Mi, Z., Meng, J., Zheng, H., Shan, Y., Wei, Y.M., Guan, D., 2018a. Data descriptor: A multi-regional input-output table mapping China's economic outputs and interdependencies in 2012. Scientific Data 5, 1-12.

Mi, Z., Zheng, J., Meng, J., Shan, Y., Zheng, H., Ou, J., Guan, D., Wei, Y. M. , 2018b. China's energy consumption in the new normal. Earth's Future.

Miller, R.E., Blair, P. D., 2009. Input-output analysis: foundations and extensions. Cambridge University Press.

Peters, G.P., 2008. From production-based to consumption-based national emission inventories. Ecol. Econ. 65, 13-23.

Peters, G. P., Marland, G., Le Quéré, C. , Boden, T., Canade11, J. G., Raupach, M. R. , 2012. Rapid growth in C02 emissions after the 2008-2009 global financial crisis. Nature Climate Change 2, 2-4.

Quadrelli, R., Peterson, S., 2007. The energy-climate challenge: Recent trends in C02 emissions from fuel combustion. Energy policy 35, 5938-5952.

Rocco, M. V., Forcada Ferrer, R. J., Colombo, E., 2018. Understanding the energy metabolism of World economies through the joint use of Production- and Consumption-based energy accountings. Applied Energy 211, 590-603.

Thomas, C. D. , Cameron, A., Green, R.E., Bakkenes, M., Beaumont, L. J., Collingham, Y. C. , Erasmus, B.F., De Siqueira, M. F., Grainger, A., Hannah, L., 2004. Extinction risk from climate change. Nature 427, 145.

Timmer, M., Los, B., Stehrer, R., de Vries, G., 2016. An anatomy of the global trade slowdown based on the WIOD 2016 release. Groningen Growth and Development Centre, University of Groningen.

U.S. Energy Information Administration, International Energy Outlook 2017.

Vogt-Schilb, A., Walsh, B., Feng, K., Di Capua, L., Liu, Y., Zuluaga, D., Robles, M. , Hubaceck, K., 2019. Cash transfers for pro-poor carbon taxes in Latin America and the Caribbean. Nature Sustainability 2, 941-948.

Wang, J., Lin, J. , Feng, K., Liu, P., Du, M. , Ni, R., Chen, L., Kong, H., Weng, H. , Liu, M. , 2019. Environmental taxation and regional inequality in China. Science Bulletin 64, 1691-1699.

Wiedenhofer, D., Guan, D., Liu, Z., Meng, J., Zhang, N., Wei, Y. -M. , 2017. Unequal household carbon footprints in China. Nature Clim. Change 7, 75-80.

Wiedmann, T., Lenzen, M., 2018. Environmental and social footprints of international trade. Nat. Geosci. 11, 314-321.

Wu, X., Chen, G., 2017. Global primary energy use associated with production, consumption and international trade. Energy Policy 111, 85-94.

Yi, K., Meng, J., Yang, H., He, C., Henze, D. K., Liu, J., Guan, D., Liu, Z., Zhang, L., Zhu, X., 2019. The cascade of global trade to large climate forcing over the Tibetan Plateau glaciers. Nature communications 10, 3281.

Zhang, P., Zhang, L., Hao, Y., Liang, S., Liu, G., Xiong, X., Yang, M., Tang, W., 2019. Understanding the tele-coupling mechanism of urban food-energy-water nexus: Critical sources, nodes, and supply chains. Journal of Cleaner Production 235, 297-307. 
